\title{
Pros

\section{Y (NO) FUERON FELICES: LA FATALIDAD DE LAS PAREJAS MIXTAS EN LA LITERATURA ESPAÑOLA COLONIAL ESCRITA POR MUJERES DURANTE EL SIGLO XX}

\author{
AND THEY WERE (NOT) HAPPY: \\ THE FATALITY OF MIXED COUPLES IN COLONIAL SPANISH LITERATURE \\ WRITTEN BY WOMEN DURING THE $20^{\text {TH }}$ CENTURY \\ YASMina Romero MORALES \\ Universidad de La Laguna \\ yasminaromero@hotmail.com
}

RESUMEN: Este trabajo tiene como objetivo analizar si las parejas mixtas -formadas por marroquíes y españoles- han logrado fraguarse, o no, en la literatura española de ficción y colonial escrita por mujeres durante el siglo xx. Para ello se ha seleccionado un conjunto de sesenta y dos textos, novelas y relatos de ficción, que tienen como fondo de sus tramas Marruecos y que fueron publicados durante el siglo pasado. La metodología usada ha sido la propia de la perspectiva de género, los estudios culturales y, finalmente, las teorías postcoloniales.

PALABRAS CLAVE: alteridad; literatura española; mujeres escritoras; parejas mixtas; literatura colonial

ABSTRACT: The purpose of this paper is to analyze whether mixed couples formed by Moroccans and Spaniards- have achieved a success, or not, into Spanish fiction and colonial literature written by women during the $20^{\text {th }}$ century. For that purpose, a set of sixty-two texts, novels and short stories with Moroccan plots and published during the last century, have been selected. The methodology used has been that of the Gender Perspective, Cultural Studies and, finally, Postcolonial Theories.

KeYWORDS: Otherness; Spanish Literature; Women Writters; Mixed Couples; Colonial Literature 


\section{INTRODUCCIÓN}

Josep Lluís Mateo Dieste comienza uno de sus trabajos recuperando una cita de Edmund R. Leach: "distinguimos a los que son de nuestra clase de los que no lo son cuando nos hacemos la pregunta: ¿Nos casaríamos con ellos?" (Leach 1967: 19 apud. Mateo Dieste 2005: 128) Y, de alguna manera, el impacto de su reflexión se convirtió en el hilo conductor de este trabajo de investigación: analizar si las relaciones entre parejas mixtas lograban fraguarse, o no, en la literatura española de ficción escrita por mujeres durante el siglo pasado.

Para ello fue necesario hallar una narrativa en la que se propiciara la coexistencia de diferentes culturas por lo que, dentro de la literatura española colonial del siglo $\mathrm{xx}$, se seleccionaron aquellas ficciones que tenían como tema central la cuestión de Marruecos, puesto que su peso era el más significativo en comparación con cualquiera de los otros diversos escenarios literarios coloniales hallados en la narrativa española del pasado siglo. ${ }^{1}$ La razón de fondo es que hay más de doscientas novelas y relatos de ficción de tema marroquí publicados en España desde mediados del siglo xix hasta el día de hoy (López García 1994; Carrasco González 2000; López Barranco 2006). Si además tuviéramos en cuenta las obras que no son de ficción, o de otros géneros literarios como pudiera ser el teatro o la poesía, repararíamos en que el interés que se ha sentido desde España por Marruecos ha sido, y es, substancialmente acusado. ${ }^{2}$ Podría pensarse que, quizá, Latinoamérica rivalizaría en este punto, en la medida que son muchas las ficciones españolas del siglo xx que tienen lugar en antiguas colonias latinoamericanas, sin embargo, dado que el interés de esta investigación era analizar las uniones mixtas, la identidad que se supone a sí misma España, en tanto etnia-raza, lengua o religión resultaba así completamente opuesta a la "otredad" marroquí imaginada y era el binomio español-marroquí, por tanto, el más fructífero a la hora de analizar dichos encuentros amorosos.

Por otro lado, para llevar a cabo esta aproximación he seleccionado como fuentes primarias novelas y relatos que hubieran sido escritos por mujeres, un criterio que arrojó un corpus fecundo compuesto por casi cinco mil páginas. ${ }^{3}$ La motivación que llevó a escoger solo mujeres fue doble. En primer lugar, compensar, de alguna manera, el olvido sistemático al que han sido sometidas las escritoras -sin duda no solo las de este tema en concreto-y que las ha condenado en la actualidad al olvido, aun a pesar del éxito que algunas de ellas cosecharon cuando publicaron sus textos. Desafortunadamente de muy pocas se recuerda

\footnotetext{
${ }^{1}$ En este trabajo de investigación se entiende por literatura colonial la definición propuesta por Carrasco González: "esa manera de narrar sobre países alejados sin pertenecer al pueblo de ellos y con un sentimiento o mentalidad mayor o menor, de alteridad" (2009: 9). Se salva así la vicisitud de que Marruecos pudiera haber dejado de ser colonia o, tan siquiera, Protectorado, en el momento de publicación de alguna de las obras analizadas.

${ }^{2}$ El motivo principal es la cantidad de acontecimientos históricos que han unido a ambas orillas desde siempre y que tienen su punto más álgido en la implantación del Protectorado Español en Marruecos durante cuarenta y cuatro años, justo hasta la independencia del país en 1956.

${ }^{3}$ El listado de obras puede consultarse en la bibliografía final de este trabajo.
} 
hoy siquiera su nombre. ${ }^{4} Y$, en segundo lugar, comprobar hasta qué punto las mujeres al narrar la otredad eran menos duras en comparación con los análogos escritores hombres, en el sentido que hayan podido confrontar su situación de subordinación y exclusión por razón de género en su país de origen, con la sumisión por etnia-raza del país que imaginaban. Dicho de otro modo, comprobar si quizá eran menos racistas o más críticas con la realidad colonial por el hecho mismo de descubrirse identificadas en el abuso.

La metodología usada ha sido la propia de la perspectiva de género que opta por una concepción epistemológica que se acerca al objeto de estudio desde la construcción y representación diferenciada por motivos de género y sus relaciones de poder. También la de los estudios culturales que prefieren una lectura ideológica de la cultura y, finalmente, la teoría crítica postcolonial.

\section{LA FATALIDAD DE LAS PAREJAS MIXTAS EN LA NARRATIVA ESPAÑOLA}

La realidad factual -que indudablemente permea las ficciones estudiadas- evidencia que desde la implantación del Protectorado Español en Marruecos y, principalmente, durante la dictadura franquista, siempre fue vista con malos ojos la intergamia hispano-marroquí, a pesar de esa supuesta "hermandad" que durante los años 40 y 50 tanto se intentó promulgar desde el régimen. Se quería evitar a toda costa franquear la línea que separaba a la sociedad colonizadora de la población colonizada, los civilizadores de los civilizados. Hasta las descripciones de las ciudades se hacían eco de esta separación: "Marroquíes y españoles invadían las plazas, las calles y las tiendas y ocupaban las mesas de los cafés y sus terrazas, pero no se mezclaban" (Nonell 1956: 12). Una segregación vista con buenos ojos desde el Occidente, ${ }^{5}$ por lo que, cuando el equipo de fútbol local incrementó la cifra de los marroquíes por su buen hacer con el balón, mermó de manera considerable el aliciente de los aficionados, un "club de futbol español donde no hay más que moros no interesa" (López Sarasúa 2000: 96).

Parece que mostrarse en contra de las uniones mixtas había sido desde siempre una constante española en sus contextos coloniales, ${ }^{6}$ muy afectados por las ideas racistas sobre la degeneración biológica que circulaban con fuerza

\footnotetext{
4 Las autoras aunadas para este trabajo de investigación son veintidós: Carmen Martel, Concha López Sarasúa, Encarna Cabello, Marisa Villardefrancos, Regina Flavio, Concha Linares-Becerra, Mari Paz Estévez de Castro, Cristina Fernández Cubas, Carmen de Burgos, María Charles, Carmen Martín de la Escalera, María Teresa de Jadraque, María Viñuelas, Blanca Ibáñez Blanco, Josefina María Rívas, Rosa de Aramburu, María Adela Durango, Margarita Astray Reguera, Rosa María Aranda, Julia María Abellanosa, Carmen Nonell y Dora Bacaicoa.

5 A lo largo de estas páginas se hará referencia a "Occidente" y a "Oriente" no porque se defienda con el uso de estos términos una perspectiva esencialista -de hecho, son conceptos bastante vagos en sí mismos- sino porque aluden a una imagen mental compartida, esta sí prejuiciada y estereotipada, obtenida de un enfoque unívoco y restrictivo.

6 Mateo Dieste nos advierte que esto mismo había sucedido ya en Cuba (2005: 137). Y, antes de eso, recordemos la Pragmática Sanción para evitar el abuso de contraer matrimonios desiguales, promulgada por Carlos III en 1776 y que se aplicó a la totalidad de colonias españolas.
} 
desde finales del siglo XIX. ${ }^{7}$ Las directrices de la administración colonial eran claras y explícitas: no intimar con la población autóctona para así no resquebrajar la relación de dominio que ponía en peligro el engranaje colonial. No se quería amistades de ningún tipo, ni noviazgos, ni los llamados amancebamientos, ni mucho menos bodas consideradas hipogámicas y un desprestigio para España.

En Pasión de moro (1925), por ejemplo, texto patriótico y escorado hacia un cristianismo conservador, la protagonista española se suicida antes de tener que intimar con un rifeño. Y, por ello, se la llega incluso a denominar una mártir (Astray 1925: 17). Esto sigue sucediendo en la totalidad del siglo de literatura analizado, abundan frases que desaconsejan estas relaciones del tipo: "Son marroquíes, y ya sabes... hay que evitar las complicaciones" (López Sarasúa 2000: 39); “ ¡Dios nos libre de estos enredos raciales!, ¡Todos terminan mal tarde o temprano!..." (López Sarasúa 2000: 212); "Dicen que sale con un marroquí. ¡El día que se entere su padre..." (López Sarasúa 2000: 21) o "¡Qué dice, mujé!, ¿qué la niña sale con un moro?" (López Sarasúa 2000: 97). Todo ello no solo cuando el marroquí o la marroquí es musulmán, también cuando es de confesión judía. En Noches de Tánger (1949), una española quiere casarse con un marroquí y le exhortan a que no lo haga por dos motivos de igual peso: que es divorciado y que es hebreo (Rivas 1949: 18).

La suerte de las uniones mixtas después de 1975 cambia de enfoque, el suelo de España se convierte en escenario intercomunitario con la recepción de inmigrantes y empieza a existir mayor permisibilidad social para estos enlaces interétnicos. Sin embargo, siguen provocando rechazos heredados como demuestra la lectura de las fuentes: "Las dos sabemos de sobra el interés que despiertan las occidentales entre los jóvenes marroquíes" (López Sarasúa 2002: 14), afirma uno de los personajes de ¿Qué buscabais en Marrakech? (2000), refiriéndose indudablemente a la búsqueda de la nacionalidad para su permanencia en España de los más jóvenes. Las marcas de identidad que inmovilizaban al "otro" en su otredad ya no son solo el pelo o los ojos negros, su religión o su lengua, sino también el no tener papeles.

Las novelas y relatos del último cuarto del siglo xx demuestran, por tanto, que la oposición española ante las relaciones amorosas con marroquíes sigue siendo la misma. No obstante, ya no se argumenta el rechazo en clave "racial", sino que cambia su retórica y léxico biologicista para hacer valer factores irreconciliables de religión: "Yo creo que el padre de Rosette no debería tomárselo muy a pecho porque, bien mirado, no es más que un problema de religión. ¡Y él no va nunca a la iglesia!" (López Sarasúa 2000: 21), O, como se dice en otro de los textos:

... pero es que no tiene nada que ver con este acercamiento descomedido; hay muchas cosas que os separan... costumbres, religión... ¿has pensado en todo esto?, ¿en qué dirá la gente...? Confiamos en tu buen juicio para que no te cieguen esos amoríos. (López Sarasúa 1988: 134)

\footnotetext{
7 Se creía que el contacto sexual con una persona que no fuera blanca contaminaba la "raza" que nacía sin mancha. Véase, por ejemplo, Stepan (1985).
} 
Es sobre todo la autora que cierra el conjunto literario examinado, Concha López Sarasúa, quien más recoge en sus tramas esta insistencia a que "religión y costumbres son el eterno problema" (López Sarasúa 2000: 43) porque "somos cristianos, nesranías como ellos nos llaman, y todavía hay diferencias" (46).

Por ser la religión un factor determinante a la hora de establecer una unión sentimental es por lo que muchas de las fuentes, dentro de los parámetros del tópico, optan por resolver el inconveniente con la capitulación del "infiel". Una voz de ecos históricos que alude a la llamada Reconquista y que se adopta en estas ficciones con visos racistas propios de la otredad colonial. Dicho de otra manera, que el o la marroquí, al que ya sabemos que se supone siempre musulmán, se convierta al cristianismo. Así, en estas tramas "civilizar" equivale a "cristianizar": "aunque mi madre pertenecía a la raza mora, al casarse se hizo católica" (Durango 1943: 20) o "únicamente se bautizó para casarse" (Abellanosa 1944: 211).

El personaje converso cumple entonces con el rol de buen nativo, para ello solo debe -como ha advertido Rana Kabbani- abandonar y renunciar a su familia y a su vida, ser sumiso, modesto y transformarse en un obediente cristiano (2008: 22-23). Sin embargo, vemos en este subgénero de colonias más muestras de resistencia ante el cambio de confesión que conversiones. Por ejemplo, el romance entre mujer española y hombre marroquí relatado en Zoco grande (1956) que cuenta con el beneplácito de la familia de ella ("yo no veo ningún inconveniente, muchacho. Es usted un excelente médico y tiene un magnífico porvenir por delante", Nonell 1956: 172), hasta que el padre de la joven descubre que el marroquí no tiene intención de convertirse al catolicismo ("No creo haber dicho nada que pudiera hacerle suponer que haya pensado en cambiar de religión", 172) y, por tanto, ya no es considerado un buen nativo. El padre de Isabel concluye: "No sabe cuánto me entristece. No quisiera causar a mi hija ningún dolor. Pero no tengo más remedio que oponerme a este noviazgo" (173). En este caso, el personaje marroquí que no quiere convertirse a la fe cristiana -dado que tiene apego a sus costumbres- es visto como una persona intolerante y obcecada. No profesa la fe considerada verdadera ni quiere convertirse a ella, es un infiel y su decisión es derivada de la radicalidad de sus creencias. Desde este planteamiento se reconoce de forma absoluta que el fanatismo es el que hace que el "otro" marroquí sea inasimilable.

El problema de la religión se mantuvo durante la mayor parte del siglo $x \mathrm{x}$ máxime en las últimas décadas cuando dejó de ser políticamente correcto hablar sobre "raza". Pero en la década de los 90 el motivo de la religiosidad opuesta a la propia también dejó de ser significativo -probablemente porque descendió el número de creyentes entre la sociedad española- y los argumentos que rechazaban las relaciones sentimentales hispano-marroquíes ocultaron su xenofobia en el esencialismo cultural. Ahora el obstáculo que impedía la consecución de una relación amorosa entre españoles y marroquíes era la cultura, una cultura que, de acuerdo con este planteamiento, se mantenía inmutable:

... tendrá musha curtura y to lo que tú quiera, pero seguro que cuando eztá con su familia come con loz deo y no dejará seguramente de rotá como un 
coshino, y luego dirá jal-hamdu-lillah! P'agraecerle a Allah la buena digestión. Pero tú qu'ha vizto, shiquilla?, ¿qu'a vizto? ¿No te da cuenta de la vergüenza pa tu padre? (López Sarasúa 2000: 99)

Al hilo de lo anterior se puede deducir, por tanto, que el amor entre practicantes de distintas fes fue un tópico del orientalismo romántico y de los siglos áureos más habitual en la literatura que en la realidad, si bien en la literatura -y aquí sí hay consonancia con la factualidad-tampoco abrazaban el buen final. Con todo, hay abundantes ejemplos de emotivas historias de amor entre personajes marroquíes y españoles, de uno y otro sexo. Se debe a la abundancia de obras del llamado género rosa entre los relatos de tema marroquí, un tipo de narrativa que por su propia naturaleza es propensa a dedicar la mayoría de sus páginas al amor entre sus personajes, tanto españoles con autóctonos y, también, entre iguales. Pero es que, además, si analizamos la narrativa española de tema marroquí escrita por mujeres y la escrita por hombres, se evidencia que la diferencia más significativa es la anecdótica de los textos: ellos prefirieron la guerra, ellas el amor (Zatlin 1989: 23-40).

La importancia de la "novela rosa" de colonias fue tal, que algunas investigadoras han sostenido que "la proliferación de estas relaciones prohibidas se atribuyó a la influencia que ejercieron en las impresionables jóvenes, seductoras obras literarias" (Martín-Márquez 2011: 305). La ironía, como también advierte la misma investigadora, es que estas tramas románticas lo que hacían era únicamente llevar la retórica de la "hermandad" que propagaba la política colonial española de Franco a sus resultados lógicos (Martín-Márquez 2011: 305).

De esta supuesta influencia de la literatura para promover romances entre mujeres españolas y hombres marroquíes, parece que era conocedora Carmen Nonell, la autora de Zoco grande (1956). Uno de los personajes de su novela, una cocinera sevillana que "leía muchas novelas y todas las mañanas las cambiaba en el carretón del mercado" (Nonell 1956: 209), aconseja a Clara, una jovencita española atraída por un soldado marroquí, que le diera una oportunidad porque "Esos moros, con sus vestimentas todas iguales, suelen ser caídes, que es una cosa así como príncipes, en su tierra. Tienen tierras, rebaños y buenos duros de plata, de los que ahora ya no van a verse en España" (209) .

La influencia de estas lecturas en la cocinera fue determinante para Clara, que "[d]ecidió conquistar al moro" (209). No obstante, y en honor a la verdad, la muchacha no tardó en descubrir que todas esas tierras y riquezas que la iban a convertir en una princesa en Marruecos, solo eran humos y espejos propios del orientalismo romántico de las novelas que devoraba la cocinera. Hassan era solo un pastor, no tenía ningún palacio, "ni siquiera un chalet" (210) y "ella debía ordeñar y guisar y fregar" (210).

No es objeto de este trabajo de investigación conocer si en la realidad se dieron más noviazgos hispano-marroquíes por la influencia de la narrativa colonial de corte amoroso, pero sí se debe admitir que estos idilios son abundantes en las ficciones aquí analizadas. El examen de las novelas y relatos devuelve muchos y diversos tipos de relaciones mixtas, ubicadas fuera de los límites nor- 
mativos y consideradas ilícitas durante una gran parte del siglo xx. Ahora bien, y como adelantábamos, casi todas ellas tienen en común una particularidad que las aleja del género rosa partidario siempre del final feliz: la fatalidad.

Las relaciones amorosas entre españoles y marroquíes que recogen las ficciones estudiadas fracasan en su inmensa mayoría y no solo no logran su fin último, el matrimonio, sino que ni siquiera consiguen mantenerse unidas. Esto es algo de lo que nos prevenía Pratt: "la lección que debe extraerse de las historias de amor coloniales [es que] siempre fracasa" (2010: 191). No te puedes casar con lo "otro", lo necesitas para definirte. Además, de sobra es sabido que el matrimonio es un símbolo de status, reservado a las personas que la ley considera iguales $\mathrm{y}$, por tanto, es lógico suponer que, en una relación de alteridad, donde un grupo se percibe superior al otro, esto no pueda estar abocado sino al infortunio: "hurgas en la memoria con la certeza de no hallar, entre todas las parejas mixtas que has conocido en Marruecos, una sola que haya sobrevivido al desastre..." (López Sarasúa 2002: 179).

Detengámonos ahora en el retrato de estas uniones mixtas separándolas entre aquellas formadas, en primer lugar, por hombres españoles con mujeres marroquíes $y$, en segundo lugar, por mujeres españoles con hombres marroquíes.

\section{LA "OtRA" MARROQUÍ Y EL ESPAÑOL: DE AMORES PASAJEROS ABOCADOS AL FRACASO}

La realidad y verdad de las relaciones entre mujeres marroquíes y hombres españoles durante el siglo xx revela que se dio en muchísima menor proporción que, al contrario, entre mujeres españolas y hombres marroquíes (Mateo Dieste 2005: 136). La literatura colonial firmada por hombres, sin embargo, ha convertido este romance con la "otra" de contexto árabe-islámico en el más frecuente, antes y después del periodo colonial. Tal vez, porque revelan un deseo occidental de apropiación de "lo marroquí" y, por supuesto, porque Cervantes lo convirtió en un verdadero tópico desde que decidiera retratar este tipo de relaciones en sus tramas, las musulmanas enamoradas de cautivos cristianos. ${ }^{8}$

Sin embargo, si comparamos la narrativa española de tema marroquí escrita por hombres y la escrita por mujeres durante el siglo $x x$, vemos que en la de ellas surgen estas uniones mixtas en muchísima menor frecuencia que en la de los escritores hombres y, también, en muchísima menor frecuencia que el binomio "otro" marroquí y mujer española. No es que no haya ejemplos, incluso desde distintos estratos y enfoques, pero en mucha menor proporción que en las novelas y relatos de firma masculina, como si las autoras fueran hostiles a su recreación en la ficción y entendieran el encuentro con mujeres locales en sus textos, sobre todo, como una distracción pasajera (Villardefrancos 1953: 20). Esto es, personajes femeninos marroquíes que trabajan como criadas y llevan a cabo breves escarceos con "sus señores" españoles, como se recoge en La llamada del almuédano (1990); prostitutas locales que mantienen relaciones sexuales con

\footnotetext{
${ }^{8}$ Véase, al respecto, Marín (2007), porque estudia ese tópico en la narrativa del siglo xIx y XX.
} 
hombres españoles, como aparecen en Tebib (1945) o en Zoco grande (1956) y, muy pocos, matrimonios, como el de Aída con Andrés. Estos tienen una hija a la que llaman Naryís y de la que piensan que "corretea feliz por el patio ajena a racismos y a los problemas religiosos que preocupan a sus padres. Algún día será libre de escoger a ese Dios en el que buscan refugio la mayoría de los humanos" (López Sarasúa 2002: 18).

Pero, como ya se ha señalado, el subgénero de colonias analizado tiene casi por convención que este tipo de relaciones amorosas no se impongan a las circunstancias y sucumban a la fatalidad. Es más, incluso a veces se dice que los niños nacidos entre mujeres marroquíes y hombres españoles están condenados a morir como castigo divino (Ibáñez Blanco 1956: 49), una suerte de "imperialismo genético" en el que no se desean hijos mestizos, híbridos, pues estos subvierten las categorías binarias desde el nacimiento y no se les puede delimitar si pertenecen al "ellos" o al "nosotros".

Es significativo el caso que se puede encontrar en El sol nace de madrugada (1953). En esta novela un médico militar, Miguel y una marroquí, Zohora, se enamoran perdidamente. Y a pesar de que él intenta que la relación prospere y "olvidar todas las diferencias de raza" (Villardefrancos 1953: 19), sus amigos cercanos le advierten que a ambos les separan "décadas de civilización" y que ella sería "lo mismo feliz contigo que con otro..., y mejor con uno como ella. No se puede cambiar la raza" (20): “Quieres que te diga lo que serás con el tiempo? Un hombre amargado, fracasado, unido a una mora vieja e irascible, cuyas babuchas habrán pisoteado la felicidad y la ambición de toda tu vida" (20). El médico, abrumado, reflexiona sobre su relación con la marroquí y llega a la determinación de no continuar con el idilio: "iCortar! Cortar por lo sano y pronto, antes de que surgiesen consecuencias más irreparables! Era lo más sensato". Y fue así como termina la relación, ni siquiera el español intenta acercar posturas, convencido de que no podrían llegar a comprenderse, de que era "una ilusión absurda" (21).

Sucede lo mismo en Tebib (1945). El protagonista se siente atraído por una rifeña y ella también por él, sin embargo, él la rechaza en todo momento porque, como le explica a ella, "Eso no puede ser. Tú eres muy guapa, pero te debes a tu raza y tus tradiciones. No puedes hacer otra cosa que obedecer y vivir como lo que eres. Tu camino está escrito y tienes que olvidarme" (Aranda 1945: 221).

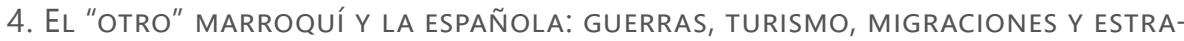 TEGIAS DE CONTENCIÓN}

En la narrativa analizada encontramos, como hemos señalado, principalmente relaciones amorosas entre hombres marroquíes y mujeres españolas, alusiones literarias más acordes con la realidad del fenómeno donde, recordemos, fueron más los hombres marroquíes que tuvieron algún tipo de idilio con mujeres españolas, que hombres españoles con mujeres marroquíes. Y es que, el correlato factual debió permear en los textos de las autoras dado que, como recogen las ficciones, muchas españolas conocieron a los africanos cuando ellos -las fuentes oficiales aseguran que más de cien mil- se trasladaron a la Península para 
combatir en la Guerra Civil española. ${ }^{9}$ También la inmigración marroquí, que ha sido especialmente masculinizada y ello ha propiciado encuentros sentimentales entre hombres africanos y mujeres españolas.

Blanca Ibáñez Blanco recoge en su novela de 1956 uno de los casos en los que la relación amorosa entre una mujer española y un hombre marroquí la facilitó la participación de este en la "guerra en España" (12). Ella lo había hecho "feliz durante los últimos años de su vida" (84), ejemplificando así "como en el amor no caben divisiones de razas" (83). Otro ejemplo lo vemos en Zoco grande (1956), donde uno de los romances del volumen es entre el marroquí Hassan y la española Clara, una pareja nacida también del contacto de los protagonistas durante la Guerra Civil española de 1936. Según se detalla en la historia, Clara había conocido a Hassan en la casa de un médico donde trabajaba: ella se dedicaba a atender a los soldados heridos y Hassan fue uno de ellos.

El conjunto literario analizado continúa dando ejemplos de hombres marroquíes emprendiendo relaciones sentimentales con mujeres españolas, aun cuando la guerra de 1936 no hubiera tenido nada que ver o fuera ya cosa del pasado. Veamos, en Zoco grande (1956), el nudo central de la novela es el noviazgo entre Isabel y Elhamid. Los jóvenes se conocen en Tánger en el centro hospitalario donde ambos trabajan. Este idilio es especialmente significativo dado que encuentran obstáculos, resistencias e impedimentos para su consecución por parte de las dos familias. Le dice a Isabel su propio hermano: "si tú cometes una acción reprobable, la mancha que caerá sobre ti nos alcanzará a toda la familia" (22). Sin embargo, el romance entre los jóvenes avanza. Llegados casi al final de la novela Isabel y Elhamid deciden contraer matrimonio, el rechazo del padre de ella es rotundo: "¿Entonces, estás dispuesta a ser la ruina moral y material de la familia?" (222-223). Recientes investigaciones mantienen que esta era la tónica factual en la España de la época, que la mujer española fuera considerada inmoral e indecente por mantener una relación con un marroquí y la rechazara tanto su familia como su vecindad (Rodríguez Mediano / Felipe 2002: 225), era "¡la vergüenza frente a las amistades!" (López Sarasúa 2000: 47).

Lo vemos también en La llamada del almuédano (1990), María se casó con Alí, deciden vivir en Marruecos y tienen una niña llamada Arquía a la que sus propios abuelos no aceptan: "Mis padres no me han perdonado nunca mi matrimonio; para ellos el haberme casado con un árabe ha sido como una cosa vergonzosa; algo que hay que esconder al resto de la familia" (López Sarasúa 2000: 148). La joven está desesperada, necesita que sus padres la perdonen y, por ello, cuando se entera que una vecina española en Marruecos está a punto de regresar a Madrid, le pide que acuda a verlos:

Pero vamos a ver. María, ¿qué es lo que tienen que perdonarte, hija mía? [...] ¡Pues no faltaba más! Es como si tu marido no fuese tan honrado como el

\footnotetext{
${ }^{9}$ Fue desde la Guerra Civil española de 1936 cuando se empezó a controlar el correo postal para vigilar las comunicaciones entre la Península Ibérica -mujeres españolas- y Marruecos -hombres marroquíes- para así dinamitar las posibles relaciones que se hubieran podido fraguar durante el contacto mantenido durante los años de la guerra. Véase el estudio realizado por Mateo Dieste (2003).
} 
mejor; más todavía, porque, ¡bien que te lo demuestra el pobre! Si voy a verles, juro que van a escucharme ese par de intransigentes; ¡vamos, que si van a escucharme! (López Sarasúa 2000: 156)

Efectivamente, todas estas parejas aparecen en los textos retratadas como transgresoras del sistema y, por consiguiente, como objeto de exclusión por parte de sus respectivas comunidades:

Al casarse con Elhamid, rompería no solo con su familia, sino también con su medio social, que no le perdonaría nunca su unión con un musulmán. Y, por otra parte, no conseguiría nunca entrar en aquel otro mundo de él. No podría vencer la desconfianza de ellos hacia la cristiana de otra raza. (Nonell 1956: 174)

Algunos romances, sobre todo al final de los cien años de literatura analizada, se dan al calor del turismo -las damas europeas "sucumbían al exotismo entre los brazos bronceados nativos, deseosos simplemente de mejorar sus maltrechas economías" (López Sarasúa 2002: 198)-, pero, sobre todo, de la migración. La migración marroquí ha sido especialmente masculinizada y ello ha propiciado encuentros sentimentales entre hombres africanos y mujeres españolas. El mejor ejemplo, el de La cazadora (1995), no solo se narra el romance entre un marroquí y una española, sino que se insiste que a ella le gustaban todos los árabes desde que tuvo su primera relación con uno, a los veintiún años. Asegura que fue entonces cuando sus "gustos se ciñeron ya a ese modelo físico y cultural, y todavía no me han abandonado" (Cabello 1995: 59). Sin embargo, incluso en este caso, ya viendo de cerca el cambio de siglo, la española encuentra innumerables e insuperables obstáculos para la buena consecución de su relación con el marroquí Nur tanto en España como en Marruecos. Leamos lo que sucede en España:

\begin{abstract}
Me descubrí enharinada de su estigma, enharinada de ser una mísera marroquí a las miradas retraídas, ausentes de calor, de aquellos españoles con que me tropezaba en las cafeterías, calles y tiendas del pueblo; como si no perteneciendo ya a su apacible mundo, en mí reconocieran a una intrusa sujeta a las ventiscas del endemoniado carácter de aquellos árabes muertos de hambre, y a sus imprevisibles y azarosas vidas, a su errar huérfano por las aceras del ordenado y codicioso pueblo. (Cabello 1995: 103)
\end{abstract}

Es más, por el simple hecho de ir con un marroquí por la calle ambos son detenidos. Se deja patente la irritación y repulsión que le supone a los agentes de policía que una mujer española haya preferido la compañía de los marroquíes -"¡Estos moros que se larguen a su país!" (46)-; no entienden que haya mujeres españolas que confraternicen con ellos y, mucho menos, que se besen - "iVenga, las caricias en otro sitio, no aquí!" (47)-; la narradora supone que se deberá a la frustración o a la envidia "de lo que un 'moro de mierda' obtenía delante de sus narices y de una nacional" (48), pero, sobre todo, a la percepción de superioridad que se tiene del español frente al marroquí, un "extranjero indeseable" (50). Contrariado, el agente trata de forjar lazos de afinidad con la joven española mencionándole sus orígenes e incidiendo en las supuestas incompatibilidades 
entre ella y el marroquí: “¿No cree que la diferencia intelectual entre usted y él es muy grande?" (77). Hallamos aquí un rigidísimo orientalismo científico que niega la posibilidad, siquiera, de que el "otro" marroquí esté intelectualmente al mismo nivel que la protagonista española. Esta, frente a las enunciaciones racistas y en otro nivel de tolerancia y aceptación de la diversidad so,lo puede ser consciente de lo "poco que [la] unía a los españoles" (51).

Pero también encuentra oposición a su relación con Nur en Marruecos. Veamos con detenimiento el diálogo que mantiene la española con el dueño de la inmobiliaria al intentar alquilar una casa en Marruecos:

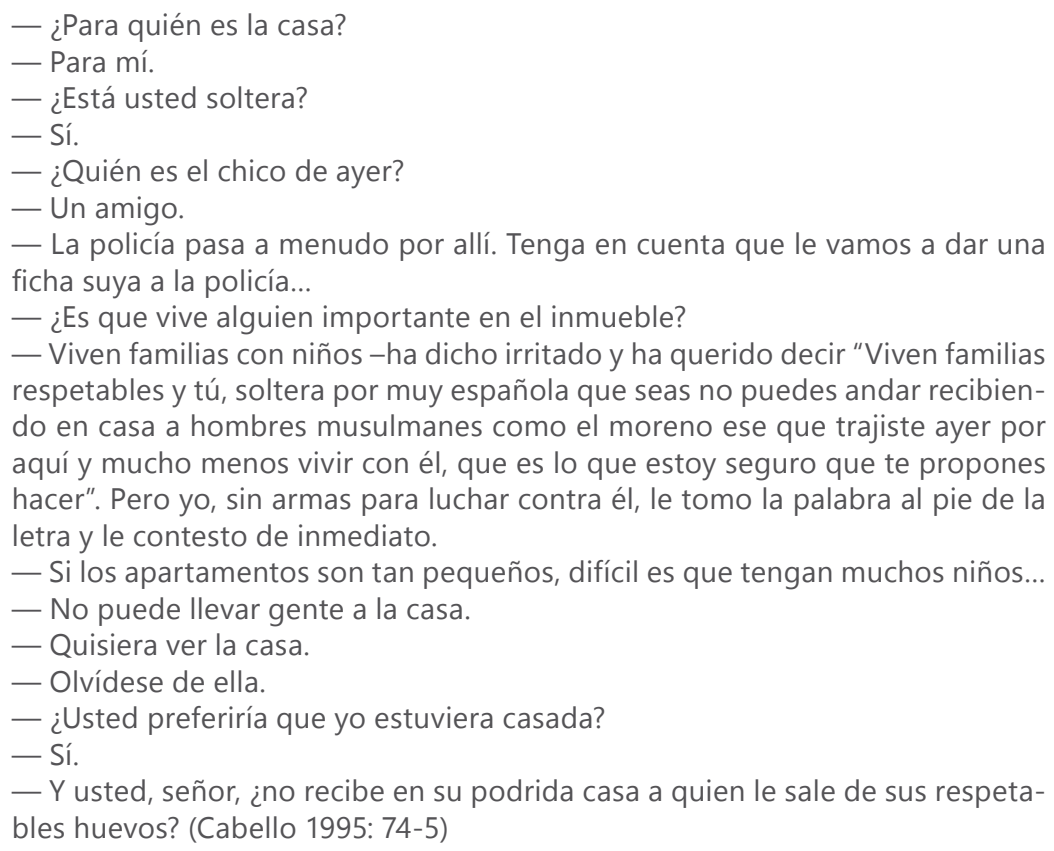

Vistas, así, las cosas, el marroquí decide no alquilarle la casa, porque su fanatismo lo lleva a defender, sin capacidad de diálogo ni acercamiento de ningún tipo, de forma rígida los mandatos de la religión que profesa. Ejemplos de este tipo hay varios, pondré uno más, el de la escritora española que vivió en Marruecos y empezó a mantener una relación sentimental con Nordín, un marroquí. El comisario del pueblo donde vivía le preguntó si Nordín era su criado, ella admitió que no lo era, que mantenían una relación conyugal y entonces la española fue expulsada a la Península. Una vez en Madrid, y para solucionar la situación de él, se casan. Sin embargo, la fatalidad a la que está condenada la relación hace que Nordín no llegue a adaptarse a la vida en España y decide regresar a Marruecos. La escritora española cree que la madre de él, la que otrora fuera su suegra, debió de influir: "No aprobaba, o más bien desaprobaba fuertemente, su relación con la extranjera" (Cabello 2000: 79). 
Una de las maneras que tuvo el discurso de izquierdas durante la Guerra Civil española para intentar evitar que estas relaciones prosperaran era asegurar que el "otro" marroquí era un ser lascivo y lujurioso, que solo le atraía de la mujer española su carnalidad. Así, las ficciones analizadas afirman que los moros son salvajes hasta en sus pasiones (Astray Reguera 1925: 12); gustan de meterse en el mar esperando que entren las jóvenes para tocarlas por debajo del agua y obligarlas a realizar tocamientos (Cabello 2000: 126-127) o intentan rozar a las mujeres occidentales en las aglomeraciones: "Procuran, con suma destreza, rozar un pecho, un muslo, agarrarte del brazo familiarmente y llamarte gacela" (López Sarasúa 2002: 148). Se asegura que saben que gustan, que atraen a las mujeres españolas, y que por ello aparece "en su semblante ese mohín, gracioso y donjuanesco, que aflora en la mayoría de los marroquíes ante las mujeres extranjeras, como si diesen por consumada la conquista" (López Sarasúa 2002: 48). Son tan lujuriosos que cualquier movimiento les excita, incluso el rezo de su propia esposa:

... siempre se pone detrás, para no excitarlo. [...] Supongo que el hecho de arrodillarse y bajar la cabeza hasta el suelo puede alterar el orden de las cosas, y no es que sea el momento más oportuno... Vamos, qué cualquier movimiento un poco raro los pone a punto. (López Sarasúa 2002: 138)

Uno de los mecanismos de demonización del "otro" ha sido siempre el insistir en su sexualidad perversa -o considerada perversa-. De ahí que en las estrategias representacionales de alteridad sobre otras culturas haya llegado a existir el mito del "violador negro". ${ }^{10} \mathrm{O}$ en el caso concreto de la otredad marroquí, el análogo "moro Juan". El "moro Juan" fue una de las representaciones que más alimentó el imaginario popular del pasado siglo xx, una suerte de don Juan violador tanto de mujeres españolas como de hombres, quien formaba parte de las tropas de Regulares que colaboraron con las filas nacionales durante la Guerra Civil de 1936.11 A tanto llegó esta imagen del moro lascivo y desenfrenado que había portadas de libros españoles que reflejaban estas violaciones, ${ }^{12}$ también poemas, ${ }^{13}$ caricaturas $^{14}$ carteles $^{15}$ e, incluso, películas. ${ }^{16}$

\footnotetext{
${ }^{10}$ Remito a los trabajos de Davis (2004: 175 y ss.) y Lott (1999: 27 y ss.).

11 Puede resultar interesante el trabajo de Eloy Martín Corrales (2002a) sobre la percepción del moro en la Guerra Civil española de 1936 por parte del bando republicano.

12 Muy conocida es la de la novela de Pedro Mata Los moros del Rif, en cuya edición de 1934 refleja a una mujer española violentada por un marroquí y llevada entre chumberas.

13 A modo de ejemplo, el poema de Domingo del Pino: "Su hogar humilde labriego/ lo profanó la morisma/ y en medio de la pradera/ todas con sayas de novia/ el pecho y el vientre rotos/ mirando al cielo con ira/ están, entre rojas flores/ sus tres mejores amigas" (Salaün 1982: 190)

${ }^{14}$ Me refiero a las ya citadas viñetas "Auca del moro feixista" [Coplas del moro fascista], editadas por la Generalitat de Catalunya y publicadas hacia 1936 donde también se recogen estas violaciones por parte de los soldados de Regulares.

15 Como el editado por las Milicias Catalanas de Madrid para favorecer el enrolamiento en su $2^{\circ}$ Batallón, Príncipe Pío. En el cartel se aprecian dos militares españoles que bayoneta en mano impiden la violación de una madre y su hija por parte de un marroquí.

16 Sirva de ejemplo una de las devastadoras escenas finales de la película Libertarias (1996) de
} 
Efectivamente, es un estereotipo tan habitual que también es de uso frecuente en esta narrativa por ser de tema marroquí. Por ejemplo, en Pasión de Moro (1925) los ojos de los marroquíes se describen como "órbitas profundas, y una luminaria siniestra de lujuria se encendía y apagaba con alternativas de faro móvil" (Astray Reguera 1925: 6), y es que se les supone a los marroquíes tal amenaza sexual, que cuando uno de los personajes femeninos, y español, de Cita en el paraíso (1941) sonríe a un marroquí, sus acompañantes, burlones, le advierten de no hacerlo, "no vaya a raptarte luego" (Linares-Becerra 1962: 129). Un dato significativo a este respecto es que en las ficciones sometidas a estudio hallamos cinco violaciones y todas ellas cometidas por hombres marroquíes, como si este acto fuera privativo de su progenie.

La verdad es que es este un estereotipo que no ha sobrevivido en la actualidad con la misma fuerza que durante el pasado siglo xx. Hoy al "otro" marroquí se le teme más por peligro a la propia seguridad física -en tanto potencial terrorista, por ejemplo- que por amenaza a la sexualidad, pero durante los años de convivencia hispano-marroquí fue un estereotipo de rentabilidad indiscutible. Sobre todo durante la Guerra Civil, ya que el bando sublevado usaba su sexualidad salvaje como una manera de atemorizar al bando republicano. Y, por el contrario, el bando republicano que insistía en retratar al bando insurrecto como afeminado -y, por tanto, incapaz de satisfacer a sus mujeres- se servía de este estereotipo para representar a las mujeres facciosas como beneficiarias del apetito sexual marroquí.

La hipersexualidad atribuida a la otredad marroquí fue una estrategia representacional que quería mantener la segregación y evitar a toda costa la hipogamia que desde el discurso orientalista español suponían las relaciones hispano-marroquíes. Las autoridades españolas no favorecían estas uniones, no querían que se rompieran las barreras entre lo marroquí y lo español, los colonizados y los colonizadores o, lo que es lo mismo, los civilizados y los salvajes, porque, de hacerlo, se fracturaba la relación de dominación. De ahí que se recurriera al imaginario compartido y se le inflara de tópicos sexuales en torno al "otro", para que se mantuvieran las fronteras de la sexualidad muy bien delimitadas. ${ }^{17}$ De esta suerte, la esfera simbólica presionaba para que estas relaciones no empezasen y, si lo hacían, no prosperaran. Uno de estos estereotipos sexuales, como se ha señalado, fue el del moro violador. Otro, fue el moro polígamo, ${ }^{18}$ porque ya sabemos, "ellos no se conforman con una sola" (López Sarasúa 2000: 212), lo más normal es que todos estén casados "y quizá con más de una mujer..." (Flavio 1938?: 57), porque se les permite "que tengan hasta cuatro esposas" (Aramburu 1937: 97), así que cuando mueren pueden dejar más de una viuda:

\footnotetext{
Vicente Aranda. Se reproduce la violación y muerte de un grupo de milicianas por parte de tropas marroquíes.

17 Las postales y las caricaturas desempeñaron un papel esencial dado que solían insistir en la enorme virilidad del "otro" marroquí por lo que la pederastia, la zoofilia o la homosexualidad eran temas recurrentes. Consúltese a este respecto Driessen (1987) y Martín Corrales (2002b).

${ }^{18}$ Aunque en realidad el término correcto hubiera sido la poliginia, dado que es el hombre el que tiene varias esposas y nunca al contrario, una mujer con varios maridos.
} 
"Algunos años antes de morirse, El Haddi había creado una nueva familia; había otra mujer y dos hijos de por medio, que vivían en Mohammedia [...] ¡Y ahora deja dos viudas!" (López Sarasúa 2000: 236).

Solo aquellas autoras con un mayor conocimiento de Marruecos relativizan la poligamia como una práctica muy poco frecuente -"hay una tendencia cada vez más extendida a prescindir de ella" (Flavio 1938: 123)-, o, al menos inhabitual, en la sociedad marroquí contemporánea. Sin embargo, el resto se hace eco del imaginario occidental que la ha entendido siempre como uno de los mayores obstáculos para la civilización, totalmente incompatible con el ideal familiar y el orden social occidental. ${ }^{19}$ El occidental es presentado como monógamo en las ficciones, al menos de manera oficial. ${ }^{20}$ Se refiere así una conversación entre españoles:

— ¿Envidias a los moros, Quin? -burlóse, sarcástica, Alicia-. Creo que tienen derecho a... ¿a cuántas esposas?

- A cuatro legítimas, el hombre libre -aclaró en el acto el Teniente-. A dos, el esclavo....

— Yo soy español y católico -replicó secamente Quin a Alicia-y quiero a una sola... Buenas noches. (Linares-Becerra 1971: 296)

Un tópico sexual más atribuido al "otro" marroquí, y que en su dimensión simbólica está relacionado con su supuesta animalidad, es su prolija fecundidad: "al final te encontrarás cargada de hijos" (López Sarasúa 2000: 46), porque todos ellos tienen "cantidad de críos" (193). La razón de fondo es que en este subgénero de colonias donde muchas tramas son ubicadas en época colonial había que evitar a toda costa que aumentasen en número los marroquíes. El discurso orientalista, en su vertiente más política, temía una invasión. Apunta Fanon que "se dice que se acuestan por todas partes y a todas horas. Son genitales. Tienen tantos niños que ya no llevan la cuenta. Desconfiemos o nos inundarán de pequeños mestizos" (2009: 143).

Otro estereotipo sexual más, y ligado a la aprensión de que la comunidad marroquí se reprodujera a un ritmo demasiado rápido, fue el del tamaño del pene: “¿Vas a decirme que no estás enterada de lo que se comenta por ahí? ¡Que la tienen muy larga!" (López Sarasúa 2000: 39), afirman algunas jóvenes españo-

19 Efectivamente la poligamia no la abolió el Islam, es más, la permite, pero también es cierto que la desaconseja (Sura IV, Aleya 129). Pese a lo que puede parecer desde criterios actuales, que Mahoma autorizara la poligamia fue una medida progresista que sirvió como protección para viudas, divorciadas o las mujeres solas, ya que obligaba a los varones a encargarse de ellas. Con todo, la poligamia en el Islam está limitada a esposas y con la condición de trato igualitario en lo afectivo y en lo material, de ello resulta que sea una práctica casi irrealizable y se tienda al matrimonio monógamo.

20 El marido de madame Ferrer en La llamada del almuédano (1990) no perdió la oportunidad de hacerla de menos con quien fuera: "isi le digo que las moras no me duraban ni una semana! Con algunas se acostó, ¡de eso tengo la certeza!, y las que no consentían terminaban por irse... Esto entre nosotras, en confianza" (López Sarasúa 2000: 74). O Carlos, el español protagonista de Noches de Tánger (1949): "En todo este tiempo, Esmeralda, traté a muchas mujeres, pero... Entiéndeme, querida, no mujeres que significasen algo para mí. En mi vida, hasta ahora, la mujer ha sido como un entretenimiento banal y agradable" (Rivas 1949: 88). 
las protagonistas de las últimas novelas y relatos. No obstante, por esas fechas ya se sabía que no tenía base científica y así se reconoce (López Sarasúa 2002: 27) ${ }^{21}$ si bien sigue funcionando en estas ficciones, y desde el imaginario simbólico español, como una técnica de contención más de lo "otro", en esta ocasión, mediante la alusión a sus excesos.

Las autoras del corpus de fuentes primarias no se detienen especialmente en cuestionar este cliché que sitúa al marroquí en el plano de la lujuria y el desenfreno, pero sí es cierto que, de confirmarse el tópico, tampoco todas muestran aprensión al mismo. La protagonista española de La cazadora (1995) ve con buenos ojos la licencia sexual marroquí. Se siente atraída por los árabes desde joven, ya que en el acto amoroso encontraba en ellos una "absoluta ausencia de sentido de culpa" (Cabello 1995: 59) y, además, le gustaba "su disponibilidad" (59). El orientalismo romántico nos da la pista en este sentido: Marruecos, y con él todo Oriente, es el lugar del sexo sin culpa, de la perversidad y la transgresión, un reverso del sexo convencional y normativizado que se encuentra en Europa.

Sea como fuere, en un caso o en otro, es de esta manera como se despoja a los marroquíes de la capacidad de poseer preocupaciones de índole social. Esta estrategia representacional consigue describirlos de forma primitiva y marginal, no tienen inquietudes sociales o existenciales, sino que se encuentran encerrados en una otredad que solo entiende de hábitos sexuales. Se les ficcionaliza marcadamente erotizados, muy fuertes, de gran atractivo corporal, brutos y, por supuesto, machistas.

Las ficciones no muestran si estos tópicos y estereotipos calaron lo suficiente para que las relaciones entre marroquíes y españolas estuvieran abocadas al fracaso y la fatalidad, pero la verdad es que muy pocas de ellas prosperaron. Lo vemos desde el primer amor mixto que encontramos en las fuentes, Pasión de moro (1925), donde ella prefiere suicidarse que estar con Abd-el-Mulek. Luego los ejemplos se van sucediendo. El amor entre la española Isabel y el musulmán Seddek termina con él asesinado o Ainalma y Mahfuz que, por amor, ella incluso se queda a vivir en Agmat, pero en el epílogo de la novela se explica que su relación no prosperó, que apenas duró seis meses y que la muchacha tuvo que regresar a España.

\footnotetext{
21 Se tiende a relacionar la eclosión de este mito sobre el pene con ritos culturales como la circuncisión, pero, como observa Fanon, esta descripción genital ha sido una constante a la hora de identificar al "otro" como salvaje -Fanon hace suyo un pasaje de Martinique (1949) de Michel Cournort para redundar en esta idea: "ya no se percibe al negro, sino un miembro: el negro se ha eclipsado. Se ha hecho miembro. Es un pene" (2009: 249)-. Moreta-Lara, por el contrario, opina que lo más probable es que el estereotipo del proverbial tamaño del pene marroquí se construyera desde el propio Marruecos y no por España (2005: 35). Como quiera que sea es un cliché que viene de lejos: el escritor Félix María Samaniego, allá por el siglo XVIII, ya lo recogía en "La Peregrinación" -había diez árabes en el desierto que "alegres manifiestan diez erguidos y gordos instrumentos capaces de empreñar hembras a cientos" (2010: 148)- y, desde entonces, ha sido objeto de un constante citar y recitar, incluso por autores de la talla de Francisco de Ayala en "La cabeza del cordero" (1948). Veamos este como último ejemplo: "Era fama que le había favorecido Alá con dotes descomunales, tanto que de ahí le venía otro apodo, bastante indecente, por el que era conocido en todo Fez, y llegó a atraerle la curiosidad hasta de la misma sultana. Ignoro si alcanzaría a satisfacerla; se cuentan salacidades" (Ayala 2006: 179).
} 
La moraleja es patente, se prefieren parejas que profesen "tu misma religión", que sean "de tu raza", porque, sin duda, es "lo más razonable" (Durango 1943: 69). De lo contrario, "Ios problemas no tardarían en surgir" (López Sarasúa 1988: 133).

\section{A MODO DE CONCLUSIÓN}

En resumidas cuentas, las relaciones sentimentales entre españoles y marroquíes no prosperan en las tramas y todos los infortunios por los que atraviesan se convierten en una advertencia para el público lector. Las parejas mixtas se enfrentan a la doble reprobación de sus respectivas sociedades y para ello se utilizan argumentos en clave de "raza", religión o costumbre. Cuando esto no es suficiente, tópicos y estereotipos degradantes de índole sexual y que subrayan tanto su lascivia como su prolija fecundidad. La idea era que funcionaran a modo de técnica de contención de su otredad, mediante la alusión a sus excesos. En ningún caso se habla de amor o romanticismo, de lo cual se colige que el vicio y la lujuria sean las únicas formas de expresión que conoce la "otra" y el "otro" marroquí, un estereotipo que el Occidente cristiano ha vertido sobre el mundo árabe-islámico desde la Edad Media. De hecho, esta estrategia representacional consigue, además, describirlos de forma primitiva y marginal, despojados de cualquier capacidad para poseer preocupaciones de índole social o existencial.

Es de esa manera como este género de colonias, que siente verdadero temor a la pérdida de las barreras étnicas y sociales, pone de manifiesto la metáfora del choque colonial donde las líneas divisorias deben mantenerse delimitadas para garantizar su perpetuación.

Finalmente, la posibilidad de una mayor sensibilidad por parte de las escritoras ante la subordinación por motivo de etnia-raza de la otredad imaginada, por el hecho mismo de ser mujeres y víctimas de la subordinación de género, no ha afectado en su tratamiento y descripción del "otro" o la "otra" marroquí. Las veintidós escritoras, de las que se han analizado únicamente sus textos de tema marroquí, se han pensado a sí mismas superiores etno-racialmente y, como suele suceder, a pesar de ser conocedoras de las opresiones que soportan por ser mujeres, no son igual de conscientes ante aquellas diferentes opresiones que ellas mismas pudieran ejercer. En honor a la verdad, estos discursos orientalistas examinados son totalmente comparables a los de los autores varones en cuanto al enfoque dado hacia la otredad, solo evidenciando pequeñas diferencias en lo tocante a la elección de contenidos, como se ha señalado y, en ningún caso, en las diversas formas de tratamiento representacional.

\section{OBRAS CITADAS}

Abellanosa, Julia Ma (1944): Y llegó el plenilunio. Madrid, Gráficas Reunidas.

Aramburu, Rosa de (1937): Ojos largos. Madrid, Editorial Española.

Aranda, Rosa María (1945): Tebib. Zaragoza, Artes Gráficas.

Astray Reguera, Margarita (1925): "Pasión de moro", Los contemporáneos (Madrid), n. ${ }^{\circ} 879$. 
Ayala, Francisco (2006): De toda la vida: relatos escogidos. Barcelona, Tusquets

Bacaicoa, Dora (1955): Zohora la negra y otros cuentos. Tetuán, Colección Manantial.

Burgos, Carmen de (1989): "En la guerra". En Carmen Núñez Rey (ed.): La flor de la playa y otras novelas cortas. Madrid, Castalia, pp. 163-218.

Cabello, Encarna (1995): La cazadora. Melilla, Textos Mediterráneos.

- (1999): El cenicero. Granada, Universidad de Granada.

- (2000): Alizmur. Barcelona, Meteora.

Carrasco González, Antonio M. (2000): La novela colonial hispanoafricana. Las colonias africanas de España a través de la historia de la novela. Madrid, Casa de África.

- (2009): Historia de la novela colonial hispanoafricana. Madrid, Sial.

Charles, María (1993): Etxezarra. Barcelona, Anagrama.

Davis, Angela (2004): Mujeres, raza y clase. Madrid. Akal.

Driessen, Henk (1987): "Images of Spanish Colonialism in the Rif. An Essay in Historical Anthropology and Photography", Critique of Anthropology, vol. 7, n. ${ }^{\circ}$ 1, pp. 53-66.

Durango, María Adela (1943): Ojos verdes. Madrid, Pueyo.

Estévez De Castro, María Paz (1954): El convoy de la muerte. Madrid, Pueyo.

Fanon, Frantz (2009): Piel negra, máscaras blancas. Madrid, Akal.

Fernández Cubas, Cristina (2009): El vendedor de sombras. Barcelona, Alfabia.

Flavio, Regina (1938?): Alma de Marruecos. Barcelona/Sevilla, Ediciones Betis.

Ibáñez Blanco, Blanca (1956): Noche nupcial sin novia. Granada, B.I.B. Imprenta José María Ventura Hita.

Jadraque, María Teresa (1954): Halima. Madrid/Cádiz, Escélicer.

Kabbani, Rana (2008): Imperial Fictions. Europe's Myths of Orient. Londres, Saqi.

Leach, Edmund R. (1967): "Characterization of Caste and Race Systems". En Anthony de Reuck y Julie Knight (eds.): Caste and Race: Comparative Approaches. Londres, Churchill.

Linares-Becerra, Carmen (1962): Cita en el paraíso. Madrid, C.L.B. Imprenta Sáez.

— (1971): Muchachas sin besos. Madrid, Cunillera.

López Barranco, Juan José (2006): El Rif en armas. La narrativa española sobre la guerra de Marruecos (1859-2005). Madrid, Marenostrum.

López García, David (1994): El Blocao y el Oriente. Una introducción al estudio de la narrativa del siglo $x x$ de tema marroquí. Murcia, Universidad de Murcia.

López Sarasúa, Concha (1988): A vuelo de pájaro sobre Marruecos. Alicante, Cálamo.

- (2000): La llamada del almuédano. Alicante, Cálamo.

- (2002): ¿Qué buscabais en Marrakech? Alicante, Cálamo.

Lott, Tommy (1999): The invention of Race. Oxford, Blackwell.

Martel, Carmen (1956): ¡Demasiado tarde! Madrid, Pueyo.

Marín, Manuela (2007): "Amar a cristianos moras. Ecos de un tema cervantino en textos españoles sobre Marruecos", Bulletin Hispanique, t. 109, n. ${ }^{\circ}$ 1, pp. 235-267.

Martín Corrales, Eloy (2002a): "Entre el 'moro' violador y el 'moro' seductor: la imagen de los marroquíes en la guerra civil según las fuerzas republicanas". En Ángeles Ramírez y Bernabé López García (coords.): Antropología y antropólogos en Marruecos. homenaje a David M. Hart. Barcelona, Edicions Bellaterra, pp. 221-236.

- (2002b): La imagen del magrebi en España: una perspectiva histórica siglos XVI-XX. Barcelona, Edicions Bellaterra. 
Martín de la Escalera, Carmen (1945): Fatma. Cuentos de mujeres marroquíes. Madrid, Publicaciones África / Instituto de Estudios Políticos.

Martín-Márquez, Susan (2011): Desorientaciones. El colonialismo español en África y la performance de identidad. Barcelona, Edicions Bellaterra.

Mateo Dieste, Josep Lluís (2003): "Pourquoi tu ne m'écris plus? Les rapports mixtes et les frontières sociales dans le Protectorat espagnol au Maroc", Hawwa. Journal of Women in the Middle East and the Muslim World, vol. 1, n. ${ }^{\circ}$ 2, pp. 241-268.

— (2005): "Amores prohibidos. Fronteras sexuales y uniones mixtas en el Marruecos coIonial". En Ana Planet y Fernando Ramos (coords.): Relaciones hispano-marroquíes: una vecindad en construcción. Madrid, Ediciones del Oriente y del Mediterráneo, pp. 128-159.

Moreta-Lara, Miguel Ángel (2005): "La imagen del moro en la literatura de la guerra civil española". En: La imagen del moro y otros ensayos marruecos. Málaga, Aljaima, pp. 19-55.

Nonell, Carmen (1956): Zoco grande. Madrid, Colenda.

Pratt, Marie Luise (2010): Ojos imperiales. Literatura de viajes y transculturación. México, Fondo de Cultura Económica.

Rivas, Josefina (1949): Noches de Tánger. Barcelona, Bruguera.

Rodríguez Mediano, Fernando, y Felipe, Helena de (2002): "La memoria de los antiguos residentes españoles en el protectorado". En El Protectorado español en Marruecos. Gestión colonial e identidades. Madrid, Consejo Superior de Investigaciones Científicas, pp. 217-245.

Salaün, Serge (1982): Romancero de la Guerra de España. 2. Romancero de la defensa de Madrid. Barcelona, Ruedo Ibérico.

Samaniego, Felix María (2010): El jardín de Venus. Barcelona, Linkgua.

Stepan, Nancy (1985): "Biological Degeneration: Races and Proper Places". En J. Edward Chamberlin y Sander L. Gilman (eds.): Degeneration: The Dark Side of Progress. Nueva York, Columbia University Press, pp. 97-120.

Villardefrancos, Marisa (1953): El sol nace de madrugada. Madrid, Biblioteca de Chicas.

- (1956): Alma. Madrid, Biblioteca de Chicas.

Viñuelas, María (1946): Los vencidos. Madrid, Aguilar.

Zatlin, Phyllis (1989): "The Civil War in the Spanish Novel: Female Perspectives", España Contemporánea, n. ${ }^{\circ} 14$, pp. 23-40. 